\title{
The opaque mineralogy of metasedimentary rocks of the Meguma Group, Beaverbank-Rawdon area, Nova Scotia
}

\author{
S.J. Haysom ${ }^{1}$, R.J. Horne ${ }^{2}$ and G. Pe-Piper ${ }^{1}$ \\ 1Department of Geology, Saint Mary's University, Halifax, Nova Scotia B3H 3C3, Canada \\ ${ }^{2}$ Nova Scotia Department of Natural Resources, P.O. Box 698, Halifax, Nova Scotia B3J 2T9, Canada
}

Date Received January 15, 1996

Date Accepted June 13, 1997

(Ref.: 1997. Atlantic Geology, 33, pp. 105-120)

\begin{abstract}
Please note that Figure 5 of Haysom et al., published in Atlantic Geology, Volume 33, Issue 2, page 111, was intended to be published in colour, not black and white as was the case. The caption in the original paper referred to different minerals based on colour, which were therefore difficult to distinguish in black and white. The reproduced figure presented here (page 250 ) has been labelled and the caption (below) modified for the black and white version. In addition, reprints including a colour version of Figure 5 are available from the second author (R. Horne), P.O. Box 698, Halifax, Nova Scotia, B3J 2 T9.
\end{abstract}

Fig. 5. Selected photomicrographs in reflected light showing opaque mineral assemblages. (a) Sample MS1003-2 (slate). Pyrrhotite with glaucodot surrounded by garnet (var. spessartine)(f.o.v. $4 \mathrm{~mm}$ ). (b) Sample MS1001-4 (slate). Muscovite oriented parallel to cleavage within second generation pyrrhotite (f.o.v. $0.5 \mathrm{~mm}$ ). (c) Sample MS1012-5 (slate). Pyrrhotite, and partial replacement by colloform pyrite (f.o.v. $4 \mathrm{~mm}$ ). (d) Sample MS1000-1 (slate). Pyrrhotite, and initial replacement of birds-eye texture pyrite along grain boundaries and internal cracks (f.o.v. $4 \mathrm{~mm}$ ). (e) Sample MS1038-1 (slate). Pyrite cubes overprinting cleavage. Grainy pyrite in right corner was probably formerly a pyrrhotite grain, now completely replaced by pyrite and quartz (f.o.v. 4 mm). (f) Sample $1012-8$ (slate). Arsenopyrite in colloform pyrite. Note the inclusion of pyrrhotite within the arsenopyrite crystal, a replacement relict (f.o.v. $0.5 \mathrm{~mm}$ ). (g) Sample MS1003-4 (slate). Chalcopyrite and glaucodot, an orthorhombic euhedral crystal, inside a pyrrhotite grain, surrounded by a corona of juxtaposed garnet crystals (f.o.v. $1 \mathrm{~mm}$ ). (h) Sample MS1003 (slate). Ilmenite crystals oriented parallel to cleavage. Garnet crystals with some inclusions of ilmenite (arrows) $($ f.o.v. $4 \mathrm{~mm}$ ). aspy = arsenopyrite; cpy = chalcopyrite; gt = garnet; glauc = glaucodot; Ilm = ilmenite; po = pyrrhotite; py = pyrite; mus = muscovite; qz = quartz. 

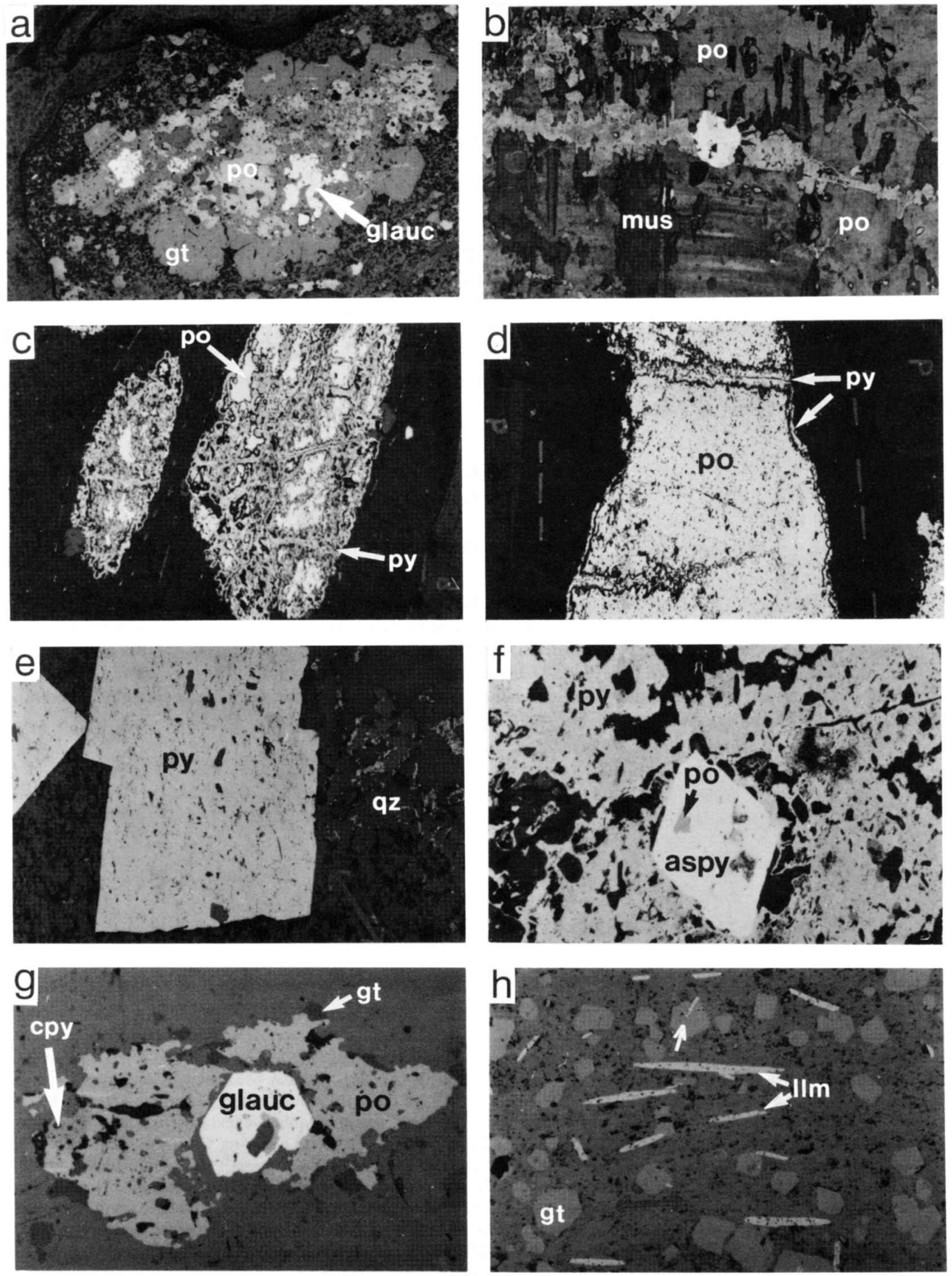